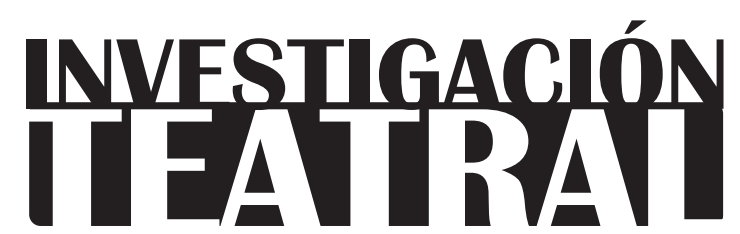

Revista de artes escénicas y performatividad

Vol. 10, Núm. 15

abril-septiembre 2019

Segunda época

ISSN impreso: 1665-8728

ISSN electrónico: 2594-0953

Universidad Veracruzana

\title{
¿Cómo será la muerte, ese cesar de sentir? (En torno a Bodas de sangre, de Antonio Gades)
}

\author{
Nidia Vincent*
}

\footnotetext{
* Facultad de Letras Españolas, Universidad Veracruzana, México e-mail:nidiadragon@gmail.com
} 


\title{
¿Cómo será la muerte, ese cesar de sentir? (En torno a Bodas de sangre, de Antonio Gades)
}

\section{Resumen}

La presente investigación se ocupa del ballet de Antonio Gades titulado: Crónica del suceso de bodas de sangre, una manifestación de danza-teatro que fue dirigida por Carlos Saura y Antonio Gades (a partir de un libreto de Alfredo Mañas basado en el drama de Federico García Lorca), y estrenada por la compañía Antonio Gades en el Teatro Olimpia de Roma, en 1974. Dicha obra se estudia con base en el registro fílmico de Carlos Saura. Se comparan los lenguajes lingüístico y corporal, aunque poniendo énfasis en los alcances poéticos de representación de este último, y entendiendo a la teatralidad desde una perspectiva teórica más amplia a partir de la propuesta de Jorge Dubatti.

Palabras clave: danza-teatro, flamenco, Federico García Lorca, poiesis, liminalidad.

\section{What would Dead, that Cessation of Feeling, be like? A Reflection on Bodas de sangre, by Antonio Gades}

\begin{abstract}
This article examines the dance-theater piece Crónica del suceso de Bodas de sangre, by Antonio Gades, using Carlos Saura's film as a register. A comparison of the language of the word and that of the body is attempted emphasizing the latter's poetic representational abilities, and approaching theatricality from a wider theoretical perspective, after Jorge Dubatti's proposal.
\end{abstract}

Keywords: dance-theater, Flamenco, Federico Garcia Lorca, poiesis, liminality. 


\section{¿Cómo será la muerte, ese cesar de sentir? (En torno a Bodas de sangre, de Antonio Gades)}

$\mathrm{E}$ 125 de julio de 1928 apareció en el periódico español $A B C$ la noticia del asesinato de un joven a manos de un enmascarado. Poco después, los extraños sucesos fueron esclarecidos: a unas horas de celebrarse el matrimonio entre Francisca Cañada Morales -llamada Paquita "la Coja"- y Casimiro Pérez Morales, la novia huyó por la madrugada con su primo Paco Montes. En el camino fueron emboscados por la hermana y el cuñado de Francisca. Paco murió a consecuencia de varios disparos; la novia escapó de ser estrangulada, fingiéndose muerta.

Una vez desvanecido el misterio, la noticia no tiene en realidad nada de excepcional: son sólo las víctimas de un crimen pasional más. Los sobrevivientes de aquel fatídico día continuaron con sus vidas anónimas. Casimiro Pérez se casó y se mudó a un pueblo cercano. Francisca Cañada, quien falleció de 84 años en 1987, vivió en soledad y retiro, marcada por los hechos sangrientos.

A este suceso se le conoce como el "crimen de Níjar" (pequeña población de Almería, provincia de Andalucía) y ha sido recreado en varias ocasiones. Muy cercano a los hechos, circuló un romance popular; en 1931, Carmen de Burgos ("Colombine") escribió la novela Puñal de claveles; un año después, Federico García Lorca terminó su drama Bodas de sangre, el cual fue estrenado poco después en Madrid; Carlos Arce publicó el estudio El crimen de Nijar. El origen de Bodas de sangre en 1998; Lola Guerrero dirigió en 2005 el documental El crimen de una novia. A estas obras se añade una secuela considerable de trabajos inspirados en la obra teatral de García Lorca.

Las pasiones y la fatalidad de este triángulo amoroso, tan real, tan común, fueron los detonantes para que algunos creadores recuperaran la anécdota desde registros particula- 
res: narrativos, fílmicos o líricos; como ficción o investigación documental; como tragedia o melodrama. De todas estas obras, la de Lorca ha sido la de mayor trascendencia, con una hondura definitivamente trágica que remite a absolutos como la existencia, la verdad, el eros, la identidad, el honor, la muerte. Testimonios de varios amigos cercanos al autor afirman que la noticia despertó su interés desde el primer momento y que el drama fue el resultado de un proceso de lenta gestación. ${ }^{1}$

Bodas de sangre, como la mayoría de las obras teatrales de Lorca, ha sido objeto de incontables montajes, en muchos idiomas y desde propuestas estéticas muy distintas. Uno de los ejemplos más singulares de su universalidad es la puesta en escena del Laboratorio de Teatro Campesino e Indígena, estrenada en Oxolotán (Tabasco, México) a las faldas de un cerro en 1983, con la participación de 180 campesinos. Esa versión libre se alejó -según reseñas del momento- de la poesía lorquiana, pero rescató la fuerza primitiva y básica que anima la historia. Casos distintos son las películas de Carlos Saura -a partir de un ballet de Antonio Gades-, y La novia (2015) de Paula Ortiz. La película de Ortiz optó por un tratamiento preciosista y por apegarse a los parlamentos originales; el ballet de Gades carece de diálogos y apuesta por la expresión corporal. Es este último el objeto del presente artículo.

\section{Crónica del suceso de bodas de sangre de Antonio Gades}

Crónica del suceso de bodas de sangre ${ }^{2}$-título original con que Gades la estrenó en Roma en 1974- es una coreografía apegada a un argumento y con marcadísimos rasgos de dramatización. Es, en sentido estricto, una paráfrasis, en tanto que imita un discurso original apelando a un lenguaje diferente. Así, desde lo corporal, espacial y musical, propone una obra artística autónoma que va más allá de la imitación, pues fue transmutada en un nuevo discurso.

Tanto el espectáculo teatral como la danza son artes de performance, hechos indisolublemente anclados a la efímera ejecución del actor o el bailarín. Esta situación fue un impedimento insalvable para la repetición, conservación y análisis de cientos de manifestaciones artísticas y culturales hasta la aparición del cine. Por ello, más allá de si un video puede

1 Así lo comentan su hermano Francisco García Lorca (ver Federico y su mundo. Madrid: Alianza, 1980, p. 320) y la biógrafa Michelle Auclair (Vida y muerte de Federico García Lorca. Ciudad de México: Era, p. 265), entre otros.

2 Además de la participación de Antonio Gades en el papel de Leonardo (el amante con quien huye la Novia en el drama lorquiano), los protagónicos estuvieron a cargo de Juan Antonio Jiménez, como el Novio, y la primera bailarina Cristina Hoyos, como la Novia. Treinta y cinco años después, la Compañía Antonio Gades reestrenó esta obra. 
capturar y transmitir, o no, el efecto estético que impone sobre el espectador la energía de un ser vivo en escena, resulta invaluable el aporte que los medios audiovisuales han brindado a la historia y estudio de la danza, el teatro y otros espectáculos. Caso muy concreto y especial es el del ballet flamenco Bodas de sangre que, gracias a la película de Carlos Saura, ha llegado a un público amplísimo, trascendiendo generaciones y entusiasmando a todo tipo de espectadores. También ha sido objeto de incontables artículos.

Cuando en 1981, Saura asistió a un ensayo de la compañía de Gades de la reposición de la obra en Madrid, decidió filmarla. Además de ser un conocedor del mundo flamenco, Saura había sido fotógrafo de ballet, lo que le permitió advertir que se encontraba ante un trabajo excepcional del que debía dejarse un registro perdurable.

De modo que el cineasta se dispuso a capturar, a través del séptimo arte, la magia del baile: fijó en una cinta memorable la momentánea belleza del cuerpo humano en movimiento; mas no se limitó a grabar una función ni optó por una adaptación cinematográfica del ballet, sino que filmó un ensayo. Como la breve duración de éste no alcanzaba los sesenta minutos mínimos que se exigen para un largometraje, Saura decidió incluir algunas secuencias a modo de introducción, en las que observamos lo que antecede a la ejecución en camerinos y en el salón de ensayos. De este modo, la película también documenta el proceso de todos los participantes y sumerge a los espectadores en el "rito" que habrá de acontecer.

Saura y el fotógrafo Teodoro Escamilla no privilegiaron el plano general -obligado en las grabaciones de danza - sino que dirigieron su atención a gestos, miradas, brazos, piernas, pies, como piezas artísticas, ofreciendo su propio punto de vista del espectáculo. La excepcional factura de esta "película-ballet" despertó gran interés y convidó a Saura a continuar con este género híbrido con filmes como Carmen (1983), Amor brujo (1986), Sevillanas (1991), Flamenco (1995), Tango (1998) y Salomé (2002).

Bodas de sangre de Carlos Saura no es la "grabación de una función de la compañía de Gades", sino una propuesta de lectura, de interpretación, un volver a relatar desde el lenguaje cinematográfico, con la firma al calce de un director que propone su propia estética y nos invita a revivir un arte fugaz.

Como dije previamente, el presente trabajo se centrará en la propuesta de Gades (aunque se tenga que partir necesariamente de un objeto de estudio mediado por una cámara), influido por la visión de un cineasta que "organiza nuestra mirada". Cabe también apuntar que la adaptación del argumento estuvo a cargo del dramaturgo Alfredo Mañas -quien

3 Para Dubatti, el cine, en tanto mediador entre un espectáculo en vivo y un espectador, anula una experiencia directa (convivio) e implica una relación determinada por lo tecnológico (tecnovivio). El cine, como el teatro, organiza la mirada de los otros y produce una óptica política (“Convivio y tecnovivio”). 
INVESTIGACIÓNTEATRAL

Revista de artes escénicas y performatividad

Vol. 10, Núm. 15

abril-septiembre 2019
¿Cómo será la muerte, ese cesar de sentir?

(En torno a Bodas de sangre, de Antonio Gades)

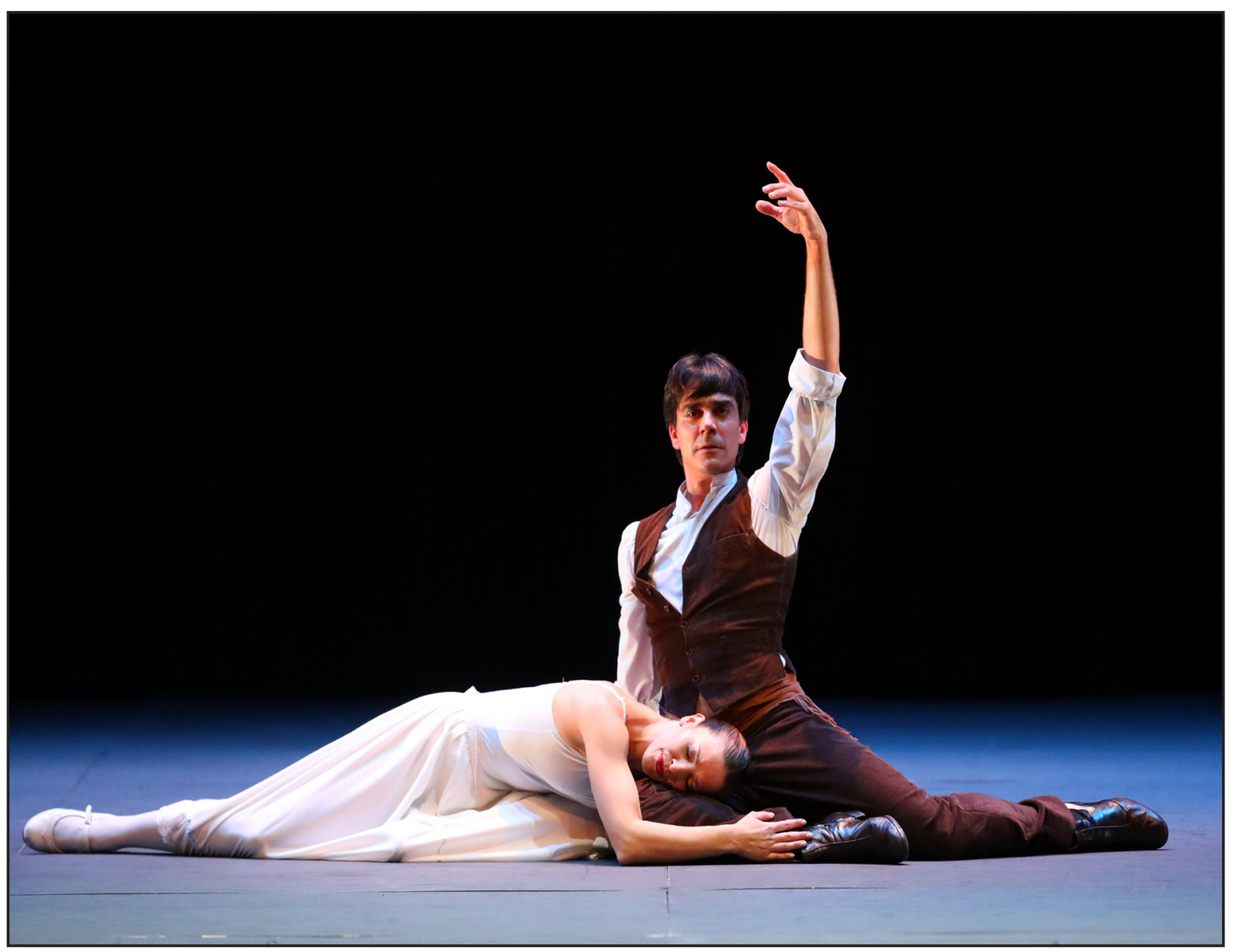

Bodas de sangre (c) Stanislav Levshin | Fundación Antonio Gades

anteriormente había escrito una versión del Don Juan (1965) para Gades-. Mañas redujo la obra a seis escenas, eliminó tres cuadros ${ }^{4}$ y personajes secundarios. Posteriormente, siguieron las coreografías que nacieron directamente de libreto y, cosa inusual, la composición musical se hizo ex profeso para la coreografía (Domínguez et al 18). Si bien Gades preservó la esencia de la obra lorquiana, su creación no es de una fidelidad ciega sometida al texto dramático, sino que éste sirvió de inspiración, de provocación para el coreógrafo.

4 La obra de teatro consta de tres actos, distribuidos en siete cuadros. El ballet eliminó el cuadro 3 del Acto I (visita del Novio y la Madre a la casa de la novia para llevarle los regalos) y los cuadros 1 y 2 del Acto III (aparición de la Mendiga y la Luna). 
La trama original de la obra de Lorca versa sobre la tragedia de un amor prohibido y la historia de muerte y venganza entre dos familias rivales. Descendientes de estas familias son Leonardo y el Novio, ambos enamorados de la misma mujer. A pesar de que Leonardo es un hombre casado y tiene un hijo, y la Novia acepta casarse con otro para mejorar la situación precaria de su familia, la pasión que los uniera pervive y lleva a los amantes a huir en plena fiesta de bodas. El Novio, burlado, sale tras ellos en compañía de varios hombres del pueblo. La Luna y una Mendiga presagian algo funesto. Los dos rivales mueren en un duelo. Las mujeres de ambas familias quedan solas y hundidas en el desconsuelo.

La línea argumental de la danza-teatro de Gades mantiene ambos motivos: el amor imposible abrasado por la fuerza de la atracción erótica y las interminables rencillas entre familias antagónicas. La adaptación conserva las temáticas de los celos y el amor maternal, pero deja fuera las diferencias económicas entre los cónyuges y las conveniencias que conlleva su unión. Los parlamentos fueron eliminados por completo, ${ }^{5}$ siendo el gran mérito de Gades el haber trasladado la intensidad del drama a danza y gestos, a la guitarra y canto flamencos, esa mezcla cultural andaluza en donde el toque, el baile y el cante se dan cita para expresar el sentimiento.

Ver una obra de García Lorca adaptada al baile flamenco no genera extrañeza. Por el contrario, resulta una traslación natural dado el temperamento y temáticas de muchos de los textos de este autor, además de que se trata de una manifestación hispana con claros vasos comunicantes con la estética de varios miembros de la Generación del 27 relacionados al Neopopulismo (como fue el caso de José Bergamín, Rafael Alberti, Gerardo Diego, Manuel Altolaguirre, Emilio Prados y el mismo García Lorca). Este último fue el más flamenco de este grupo de poetas cultos, como hizo patente en sus volúmenes "Importancia histórica y artística del canto primitivo andaluz llamado 'cante jondo"' (1922), "Arquitectura del cante jondo" (La Habana, 1930) "Juego y teoría del duende" (Buenos Aires, 1933) y sus poemarios: Poema del cante jondo (1931) y El romancero gitano (1924-1927).

El papel que el compositor Manuel de Falla y Federico García Lorca jugaron para la expansión y revaloración del arte gitano andaluz es innegable. Si bien hay errores e imprecisiones en los artículos de Lorca -dado que no son el resultado de investigaciones rigurosas-, su importancia reside en haber captado la desgarradora y auténtica vena popular del flamenco. En opinión de Daniel Pineda:

Federico no fue un erudito en el tema; fue -lo hemos dicho- un exegeta; un cantor lírico, un intérprete del dramatismo de "lo flamenco". Pero tenía una genialidad innata

5 Sólo se mantienen del texto de Lorca la alboreá "Despierte la novia” y una nana, cuya letra es un presagio funesto. 
y un oído fino, agudo, para captar la música. No olvidemos que era un notable pianista y sabía, incluso, tocar la guitarra. Y de Falla, su gran maestro, aprendió todo lo que se sabía, hasta 1922, sobre esta temática (175).

Resulta pertinente hacer un paralelismo entre esta revaloración emprendida por Lorca y de Falla -cuando el gobierno republicano dio su apoyo incondicional a la música con reformas en la enseñanza, formación de orquestas y difusión de las manifestaciones musicales populares-, y la labor que Antonio Gades y otros entusiastas emprendieron, en pleno franquismo, ${ }^{6}$ para resignificar el flamenco y sustraerlo del folclorismo simple al que el régimen lo había suscrito, reduciéndolo a un artículo para turistas. Así como Manuel de Falla concertó en sus composiciones lo clásico y lo andaluz, Gades, ${ }^{7}$ con su personal estilo, reunió la técnica del ballet clásico con la espontaneidad y pasión de lo popular, y se convirtió en un referente para mucho de lo que habría de acontecer desde entonces en la historia subsecuente de este baile.

\section{Ballet-flamenco o danza-teatro}

Bodas de sangre de Gades corresponde indudablemente al género conocido como ballet-flamenco; no obstante, cabe ampliar esta perspectiva al concebirlo como ballet dramático o danza-teatro. ¿Y por qué no? Finalmente, lo que importa para la presente investigación es acercarse a este género de manifestaciones, caracterizadas por sus formas híbridas y liminares, a partir de las teorías del investigador argentino Jorge Dubatti, quien reconoce en el teatro tanto su tradicional naturaleza dramática, como una no-dramática, y plantea verlo como una "zona compartida de intercambio o combinación" ("Teatro-matriz y teatro liminal" 86).

La obra de Gades que nos ocupa es un ballet-flamenco, entendiendo como ballet una danza apegada a un argumento, y como flamenco, una escuela o estilo específico de música y baile andaluces. Puede decirse que el ballet-flamenco, ese nuevo formato que salió de los

6 Gades fue hijo de un republicano y él mismo fue antifranquista y un socialista convencido. Un dato interesante que refleja su postura política es que, a pesar del éxito que estaba teniendo en París Crónica de un suceso: Bodas de sangre, Gades disolvió la compañía y se retiró de la escena en un acto de protesta por los últimos fusilamientos del franquismo en septiembre de 1975.

7 De importancia semejante a la que previamente tuvo el bailarín, coreógrafo y teórico Vicente Escudero (1888-1980), quien estableció normas para el baile flamenco, lo revolucionó y se interesó por transmitirlo. Él apadrinó a Antonio Gades. 
cafés cantantes para pasar a los teatros, tiene sus antecedentes -así como la danza-teatro alemana los tuvo en la vanguardia expresionista de las primeras décadas del siglo $\mathrm{xx}$ - en dos legendarios estrenos: El amor brujo, en 1915, en Madrid, del compositor Manuel de Falla, a partir del libreto de María de la O Lejárraga, ${ }^{8}$ y El sombrero de tres picos, en 1919, por la compañía de Serguéi Diaghilev y la participación de Picasso en el diseño de escenografías y vestuarios.

Esos novedosos espectáculos flamencos, pensados para espacios más amplios, se apegaban a una línea argumental acompañada de composiciones musicales más elaboradas que las melodías populares, que podían incluir o no al cantaor y la guitarra, y que sumaron, al igual que la ópera o el ballet clásico, escenografía, vestuario y luces. El baile flamenco, caracterizado por su libertad de improvisar y no verse limitado a una coreografía o un tema específicos, perdió su natural espontaneidad, pero se fortaleció como "un baile colectivo, sistematizado y más academicista" (Brao 53). Sin embargo, no fue sino hasta la década de los setenta, después de su largo tránsito por los tablaos, que resurgió un baile flamenco teatral, cuyos representantes -entre ellos Gades $-{ }^{9}$ incursionaron en una nueva estética que sumó la expresión corporal y actoral al dominio de la técnica dancística, dio mayor peso a la dramaturgia y utilizó escenografías simples para los fondos, e iluminación muy sobria. A pesar del escaso número de producciones en este formato, fueron un parteaguas indudable para el baile flamenco de la época (78).

Ahora bien, el término "danza-teatro" suele remitir a la propuesta surgida en Alemania, con las coreografías de Pina Bausch ${ }^{10}$ en la década de los setenta. Bausch rompió con las formas estético-expresivas imperantes, sustituyendo el entablado clásico por superficies simples, integrando a su compañía a bailarines que no cumplían con el ideal de belleza clásica e incluyendo movimientos cotidianos, toscos, por completo ajenos a la danza clásica. Un sello particular de sus coreografías fue la inclusión de una especie de "relato" sin tiempo y espacio definidos, que se desarrollaba en episodios organizados en una estructura no lineal, a partir de acciones escénicas simultáneas o fragmentadas a modo de collage. Los espectáculos de Bausch dejan -incluso en grabaciones- un vivo impacto en el espectador, quien ya no sólo admira y disfruta el dominio de la técnica, sino que se ve enfrentado a una obra que produce "sentido". Un sentido que despierta curiosidad, invita a ser interpretado y conduce a un horizonte de emociones más amplio.

8 El libreto fue atribuido a Gregorio Martínez Sierra, pero de acuerdo con investigaciones recientes fue escrita por su esposa, María de la O Lejárraga.

9 José Granero, Mario Maya, Manuela Vargas, Curro Vélez, José Camborio, entre otros.

10 Pina Bausch (1940-2009) fue directora de la compañía Tanz-theater de Wuppertal, desde 1972 hasta su muerte. 
Si bien todos estos rasgos son los que caracterizan a la escuela de Bausch, nada impide extender el uso del término danza-teatro, y recuperar el sentido original del binomio que lo conforma y que desde su nombre lleva implícita la constante disputa del arte de la danza, esto es: la oscilación entre su autonomía o sujeción frente a una tradición mimética que le exigiría ser una "representación". Como lo explica la investigadora y coreógrafa argentina Beatriz Lábatte:

[...] la tensión entre estos dos extremos, entre el placer de hacer y la necesidad de decir, entre la fuerte presencia de la materialidad real del cuerpo, del espacio y de la dinámica del movimiento y lo que esto material viene a sustituir, lo que viene a 'representar', va a signar toda la historia de la danza del espectáculo occidental, desde aquella primera manifestación, allá por los finales del siglo XvI, ${ }^{11}$ hasta hoy. Inclinando la balanza en un sentido o en otro según los períodos y según los diferentes creadores (12).

Este tipo de relación, a veces natural, incluyente y de mutuo enriquecimiento; otras, de ruptura y radicalismo, puede también trasladarse a las controversias entre texto literario (palabra) versus espectáculo y corporalidad del actor, que tanto ha ocupado a creadores y teóricos del teatro del siglo xx y xxi. Hoy, por ejemplo, el "teatro del cuerpo" o "teatro físico" pone énfasis en la técnica y el control del actor sobre sus instrumentos básicos (voz, rostro y cuerpo), dejando en segundo término el argumento. Para esta corriente, el auténtico lenguaje teatral es pantomima, danza, circo, ruidos, y el actor debe formarse como un acróbata, un bailarín, un cantante, un gimnasta, pues sus movimientos y voz (o ruidos) serán signos capaces de producir efectos catárticos en el receptor.

Esta postura es heredera de varias tendencias del siglo $\mathrm{xx}$ que experimentaron alejándose de la anécdota, de la representación de la realidad, incluso de la lógica verbal, para centrarse en la energía corporal, la voz en sí, más allá de un lenguaje transmisor de sentido verbal. Directores esenciales del siglo xx dieron un papel preponderante a la corporalidad (J. Copeau, Meyerhold, Artaud, Grotowski, Decroux, Brook, Barba). Antonin Artaud, desde los años treinta, objetó la centralidad del diálogo para buscar una poesía espacial y corporal; un estado anterior al lenguaje, mediante signos, "jeroglíficos animados" generados por los gestos, actitudes y ruidos de los actores, que pudieran revelar un sentido liberado de la atadura de las palabras (60). Este distanciamiento del texto literario ha llevado a replantearse el concepto de "teatralidad" con márgenes más amplios y flexibles.

Aquí, Lábatte se refiere a los ballets de corte del renacimiento italiano, organizados por Catalina de Medici: Le Paradis d' Amour, Ballet de Polonais y, el más importante, Ballet Comique de la Reine (1581). 
Respecto a este último punto, resulta pertinente la propuesta Jorge Dubatti, quien ha replanteado la naturaleza de la teatralidad desde América Latina, proponiendo categorías y rasgos que amplían la concepción tradicional del término.

Dubatti $^{12}$ extiende los límites del concepto de teatro a todo aquello que sea un convivio teatral, es decir, una relación dialéctica de las presencias de los cuerpos, de personas que asisten, se reúnen, coinciden en un territorio, miran, aceptando el reconocimiento del otro y de uno mismo en un encuentro que no los deja indiferentes (ver "Convivio y tecnovivio"). Concibe al teatro asociado a una matriz de tres variantes: 1. el acontecimiento teatral, caracterizado por la imprescindible presencia y relación de los cuerpos, sin ningún tipo de intermediario; 2. el lenguaje poético, instancia en donde la materialidad de los cuerpos se desvía de su sentido natural para asumir otro distinto al real, de carácter poético; y 3. la expectación, esto es, la participación del espectador (ver "Teatro-matriz y teatro liminal”).

Salta a la vista que a Dubatti lo anima la intención de problematizar para dilatar, emancipar, el concepto de lo teatral. Bajo esta perspectiva inclusiva, es posible acercarse a la danza-teatro como a una manifestación de la teatralidad (más allá de la escuela de Bausch). Y ver, en el caso de Bodas de sangre de Gades, una manifestación poética y liminar ${ }^{13}$ acorde con las ideas de Dubatti:

[...] si el drama absoluto propone un teatro centrado eminentemente en la palabra, el teatro liminal pone el acento en la ausencia de palabra, en el cruce de la palabra con el movimiento, la música, la plástica, los objetos, con otras disciplinas. Ejemplos: el teatro-danza, el teatro musical, la titiritesca, el teatro físico, el happening, la instalación, teatro del relato, magia, teatro de las artes audiovisuales [...] (“Teatro-matriz" 91).

Crónica del suceso de bodas de sangre fue (y sigue siendo en cada nueva representación $)^{14}$ un convivio teatral en el que se dan cita los espectadores y el cuerpo de los bailarines sin la

12 Dubatti parte de tres nociones teóricas, que no serán tratadas en este trabajo, pero que es necesario mencionar como los ejes de su teoría: "liminalidad", "teatro-matriz" y "organización de la mirada" (ver “Teatro-matriz y teatro liminal”).

13 "No hay teatro sin liminalidad. Llamamos liminalidad a la tensión de campos ontológicos diversos en el acontecimiento teatral: arte/vida; ficción/no-ficción; cuerpo natural/cuerpo poético (en todos los niveles de ese contraste: enunciado/enunciación, constructo poético/construcción poética); representación/ no-representación; presencia/ausencia; teatro/otras artes; teatralidad social/teatralidad poética; convivio/tecnovivio, etcétera. En su plano más abarcador, dramático/no-dramático" ("Teatro matriz" 87).

14 Esta coreografía forma parte del repertorio regular de la Compañía Antonio Gades y se presenta junto con la Suite Flamenca. En noviembre de 2018 fue representada en San Petersburgo. 
intermediación de una cámara, y la presencia física y acciones de estos artistas se desvían de su sentido cotidiano para provocar asombro, extrañeza, contemplación, posiblemente placer. Sobre el carácter poético del convivio teatral de este ballet-flamenco se hablará a continuación, siguiendo a Dubatti.

\section{Estilo del montaje: sobriedad y realismo}

Por otra parte, es muy importante señalar que el montaje que nos atañe se distanció del flamenco tradicional, folclórico, colorido, espontáneo y popular. La estética de este ballet se caracteriza por la sobriedad y un minimalismo que remite a una conceptualización elaborada, culta y moderna, propia de la década de los setenta, como es el caso también de la danza-teatro de Bausch.

En Crónica del suceso... los vestuarios son básicamente en blanco y negro, se utiliza una reducida utilería de mano y la escenografía es mínima (apenas tres sillas para los guitarristas, tres ventanales grandes y la presencia del amplio espejo y el piano, característicos de un salón de ensayos). El atavío de este austero diseño está en el ritmo, los desplazamientos y la música: guitarra flamenca, una alboreá, una seguiriya, un pasodoble, una rumba y una emotiva nana. Gades era de la idea de que con la madurez, el trabajo artístico va prescindiendo de los elementos decorativos, por eso su estilo es más mesurado, tanto en los pasos como en el movimiento de brazos y manos, que el flamenco de tradición popular. Para José Luis Navarro y Eulalia Pablo, el estilo de Gades era "contenido, elegante y radicalmente varonil. Un baile depurado y perfeccionista, con movimientos arrogantes, estilizados y geométricos" (citado en Brao 81).

Llama la atención que, a pesar de la libertad que puede permitir la danza para representar personajes fantásticos o alegóricos, se excluyeron todos los que tenían carga simbólica que aparecen en la obra original (como son la Luna, la Mendiga y la Niña), lo que dio como resultado una pieza estilizada pero de un realismo impactante, apenas aliñado con un mínimo de objetos simbólicos (como son la navaja, el caballo, los azahares, el fajín, la sangre, el río). Con todo, haber optado por el realismo es un acierto de la adaptación, en virtud de que esta obra pertenece a la llamada "trilogía de la tierra española", donde García Lorca, tras su incursión en el surrealismo con Así que pasen cinco años y El público, optó por la corriente realista, quizá por ser el momento de su compromiso con el teatro itinerante de La Barraca y los ideales de la Segunda República.

Resulta especialmente interesante que la coreografía utiliza el procedimiento de mise en abyme, teatro dentro del teatro, cuando el Novio y la Madre interpretan para sí la boda que está por celebrarse, o cuando se incluye el baile de la celebración de la boda en la co- 
reografía. Otro recurso empleado, en este caso propio del cine, es aquel en que los bailarines se congregan y posan para que se tome la fotografía de la boda, y al mismo tiempo simulan -como en un cuadro congelado- la imagen estática capturada por la cámara como testimonio de ese momento.

\section{El lenguaje del cuerpo}

Antes de proseguir, conviene recordar que Bodas de sangre, el ballet, está apegado a un argumento. Los bailarines encarnan a personajes concretos e interpretan acciones específicas que dan cuenta de una historia, de modo que esa larga convivencia entre baile y teatro, "entre el placer de hacer y la necesidad de decir" -como lo describe Lábatte- se dan una nueva cita en esta coreografía, concediendo un lugar preponderante al original lorquiano.

Es obvio que siempre será un problema la correspondencia entre baile y escritura, pero como afirman Isabel Naverón y Amparo Écija en "Leer, bailar, escribir": "En cualquiera de los casos, escribir o bailar, es trazar una historia posible, hacerse consciente de ella, interrogarla" (párr. 4). De modo que para dar su justo valor a las Bodas de sangre de Gades, es preciso detenerse en lo que la danza narró y sus estrategias para hacerlo.

Al bailaor de flamenco se le prepara en las técnicas específicas de este baile y se le lleva a buscar un lenguaje corporal propio. Este lenguaje, pre-verbal, extra-verbal y paralingüístico, traduce y transmite información objetiva y situaciones emocionales a través de la corporalidad con un énfasis muy particular en el movimiento de manos, la gestualidad y el taconeo que, además de ajustarse a una técnica y buscar el virtuosismo, son altamente expresivos y significativos.

En el caso concreto de la Compañía de Gades destaca una técnica impecable, sobria, moderna y la predominancia de lo "representativo", dado que es una coreografía en donde los bailarines "actúan" apegados a un argumento y son pocos los pasajes en que el baile se aleja de contar. Pero centrémonos en algunos detalles para revisar cómo, desde el lenguaje de la danza y a través de la mediación de la cámara, llegan a nosotros estos sucesos y su intención poética. ${ }^{15}$

15 La focalización de la cámara y la edición determinarán, por supuesto, nuestra recepción, la cual no sería la misma si estuviésemos frente al espectáculo en vivo. Por ejemplo, una toma desde el cenit del escenario, o los primerísimos planos a una mirada ilusionada, o a la furia ciega que transmite un taconeo, son escenas que dependen de la mediación de la cámara. Composición de cuadros, relación sintáctica entre planos, contrastes psicológicos entre tomas de campo y contracampo. 
INVESTIGACIÓNTEATRAL

Revista de artes escénicas y performatividad

Vol. 10, Núm. 15

abril-septiembre 2019
¿Cómo será la muerte, ese cesar de sentir?

(En torno a Bodas de sangre, de Antonio Gades)

Nidia Vincent

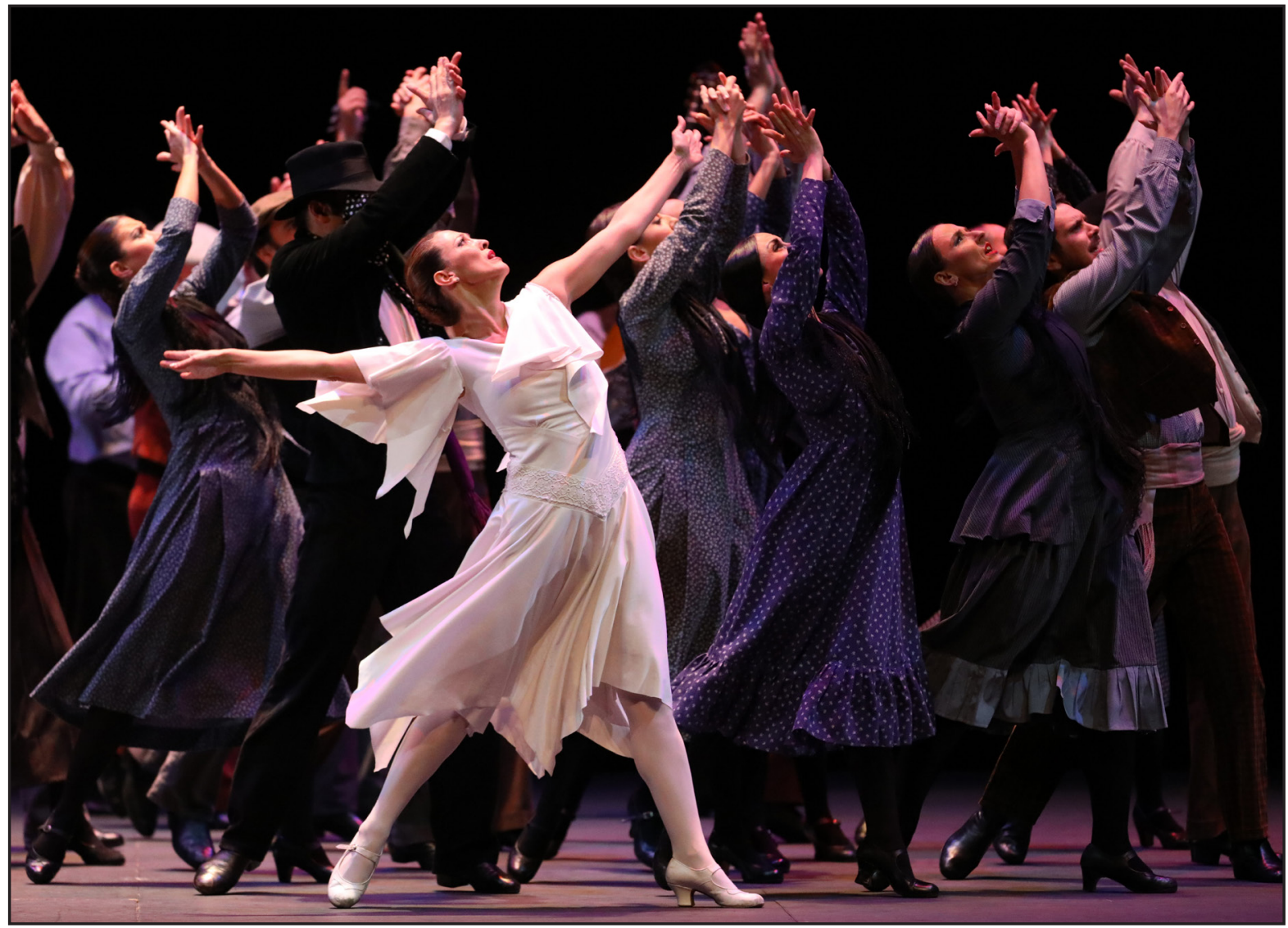

Bodas de sangre (c) Stanislav Levshin | Fundación Antonio Gades

\section{Navajas y presagios}

Dentro del universo lorquiano, se encuentran los puñales, pequeños y letales, escondidos en el fajín, prestos a desenvainarse para hundirse y acabar con la vida del adversario. "En la mitad barranco / las navajas de Albacete / bellas de sangre contrario / relucen como los peces", las describe el poeta en su poema "Reyerta". En el drama se resalta desde la primera escena su carácter negativo y su sola mención es un presagio, dice la Madre: "La navaja, la navaja... Malditas sean todas y el bribón que las inventó” (1082). Los puñales serán resaltados en la película con énfasis de las actuaciones, close-ups o cuando, en camerinos, uno de los bailarines prueba y saca brillo a su cuchillo. Principalmente, resultan protagónicos en las escenas en que la Madre quita el cuchillo a su hijo, y otra donde, enfáticamente, se lo entrega para que cumpla con su deber; así como en la contienda final. 
Gades conservó señales de presagio trágico, con gestos y miradas de la Madre y la Novia, con el paradójico desconsuelo de la alboreá ${ }^{16}$ que se canta para levantar a las muchachas el feliz día de su casamiento, en el tono de la tristísima nana con que arrullan al hijo de Leonardo y su mujer. Música, voz y letra conmueven y anuncian desdicha, a la vez que se introduce la figura del caballo herido:

Nana, niño, nana

del caballo grande

que no quiso el agua.

El agua era negra

dentro de sus ramas.

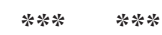

Las patas heridas, las crines heladas, dentro de los ojos un puñal de plata (1094).

\section{El caballo}

Se dijo previamente que en la adaptación se habían eliminado personajes de carga simbólica; sin embargo, Gades conservó y resaltó otros elementos emblemáticos de la estética de Lorca, como son los colores blanco y negro, la sangre, los azahares, las navajas y el caballo. Este último aparece de forma recurrente en los textos del granadino. Su propia naturaleza animal remite a fuerzas básicas, por encima de la razón o las normas sociales. Su ímpetu se impone a la voluntad y el decoro.

El caballo es símbolo de lo viril, lo instintivo y la vida (La casa de Bernarda de Alba), de la muerte (los oscuros caballos de la Guardia Civil o el caballo negro de algunos poemas), del ensueño y el amor (el caballo blanco de Santiago apóstol y de El público).

En Bodas de sangre, el caballo vuelve a representar al hombre, la fuerza sexual masculina que requiere de la hembra, y -como le confiesa a la Novia- caballo y jinete son uno:

16 La alboreá es un cante de las bodas gitanas. Proviene de albor, luz del alba, y se relaciona con la virginidad y desfloración de la novia. Por superstición, algunos gitanos no aceptan cantarlo fuera de una boda. 
LEONARDo. Pero montaba a caballo

y el caballo iba a tu puerta.

Con alfileres de plata

mi sangre se puso negra,

y el sueño me fue llenando

las carnes de mala hierba (1168).

O como en el diálogo entre el Novio y un Mozo, en el cual, el primero afianza la primacía de su masculinidad:

NOVIO. Por aquí

Mozo 1. No los encontrarás.

NOvio. (Enérgico) ¡Sí los encontraré!

mozo 1. Creo que se han ido por otra vereda.

Novio. No. Yo sentí hace un momento el galope.

Mozo 1. Sería otro caballo.

Novio. (Dramático) Oye. No hay más que un caballo en el mundo, y es éste. ¿Te has enterado? (1162).

Y será precisamente sobre un caballo que los amantes huyan, será el galope lo que los delate y será montando otro caballo que el Novio les dé alcance. Para representar este pasaje, los bailarines son a la vez caballo y jinete; simulan el paso del animal con sus pies y las actitudes de los jinetes del tronco a la cabeza. No es el trote rápido o desesperado de los perseguidores o fugitivos lo que se imita, sino un paso acompasado, mesurado, que por un lado permite seguir al grupo encabezado por el Novio, que busca vengar el honor, y por el otro, a la pareja que cabalga sincrónica y enamorada, sin la intención de escapar, en cuyos rostros se asoma la resignación y la conciencia de un amor marcado por la fatalidad.

\section{La pasión}

Tema central de la tragedia es la pasión, cómo ésta domina a los amantes y los lleva a desafiar las convenciones sociales. La fuerza de la atracción y el hondo conflicto que hunde a la pareja de amantes son expresados por el poeta en elocuentes versos:

LEONARDO. ¿Qué vidrios se me clavan en la lengua!

Porque yo quise olvidar 
y puse un muro de piedra entre tu casa y mi casa. $* * \% * \%$

Pero montaba a caballo

y el caballo iba a tu puerta (1167-1168).

NOViA. ¡Ay qué sinrazón! No quiero

contigo cama ni cena

y no hay un minuto del día

que estar contigo no quiera,

porque me arrastras y voy,

y me dice que me vuelva

y te sigo por el aire

como una brizna de hierba (1168).

La Novia desea unirse a su prometido y reconoce en él cualidades para una vida próspera, pero es imposible que se resista a su destino y a su deseo:

NOVIA. [...] tu hijo era un poquito de agua de la que yo esperaba hijos, tierra, salud; pero el otro era un río oscuro, lleno de ramas, que acercaba a mí el rumor de sus juncos y su cantar entre dientes. Y yo corría con tu hijo que era como un niñito de agua, frío, y el otro me mandaba cientos de pájaros que me impedían el andar y que dejaban escarcha sobre mis heridas de pobre mujer marchita, de muchacha acariciada por el fuego. Yo no quería, ¡óyelo bien!, yo no quería. ¡Tu hijo era mi fin y yo no lo he engañado, pero el brazo del otro me arrastró como un golpe de mar, como la cabezada de un mulo, y me hubiera arrastrado siempre, siempre, siempre, aunque hubiera sido vieja y todos los hijos de tu hijo me hubiesen agarrado de los cabellos! (1179).

Esta fuerza de atracción que anima toda la trama, está representada en la danza-teatro sobre todo en tres momentos:

1. En la tercera escena, donde con absoluta libertad -ya que no corresponde a ningún fragmento del drama de Lorca- se impone un lirismo coreográfico y plástico que iguala al erotismo expresivo de las palabras: ${ }^{17}$

17 En la película, la escena está focalizada mediante una inesperada toma cenital; la cámara capta la coreografía en que se representa cómo los amantes se desean, con desesperación, a la distancia. Los movi- 
Escena tercera: Leonardo se queda solo en el escenario, pensativo, mirando a la lejanía, evocando a alguien. Ese alguien está lejos, pero la imaginación de Leonardo borra la distancia y su deseo se materializa: aparece la Novia, que en enaguas y corpiño, se deja vestir para la ceremonia de la boda. Da comienzo la danza del amor oculto. Leonardo abraza imaginariamente a la Novia. La Novia, en su casa, acaricia su propio cuerpo como si sus manos fuesen las manos de Leonardo. En este acto de amor imaginario, Leonardo y la Novia toman su deseo por realidad, y se encuentran bailando juntos una danza llena de lirismo y sensualidad. En este momento entra la mujer de Leonardo y la ensoñación de Leonardo se desvanece (Domínguez et al 13).

2. Posteriormente, cuando en plena fiesta de la boda (cuarta escena), un pasodoble es el pretexto para que los cuerpos de Leonardo y la Novia vibren al entrar en contacto.

3. Y por último, cuando la pareja huye a caballo (quinta escena), episodio en el que la mujer se ciñe a la espalda del amado, recuesta en él su cabeza, y ambos bailarines parecen desplazarse sobre un caballo mediante el solo desliz de sus pies. La ausencia de música y cantos produce un efecto de suspense, intensificado por el roce rítmico de los zapatos sobre la duela tanto de perseguidos como de perseguidores.

\section{Rivalidad}

El otro gran tema central y fuente de conflicto en el drama es la rivalidad: una añeja disputa entre familias y el antagonismo entre dos varones enamorados de la misma mujer. Gades da un tratamiento relevante a este asunto, al que dedica la sexta y última escena de la danza-teatro (correspondiente al cuadro último del segundo acto y al tercer acto en la obra original). Mientras que el ballet muestra en escena la persecución, la huida y el duelo entre ambos rivales, en el texto de García Lorca estos pasajes son anunciados o descritos por otros personajes, por ejemplo, en un diálogo entre la Criada y la Esposa: “ ¡Han huido! ¡Han huido! Ella y Leonardo. En el caballo. Iban abrazados, como una exhalación” (1153); un parlamento entre el Novio y uno de los mozos u otro de la Luna agorera y delatora: "Ya se acercan unos por la cañada y el otro por el río. Voy a alumbrar el río" (1161); además de comentarios de los leñadores a modo de coro clásico: "El novio los encontrará con luna o sin luna. Yo lo vi salir. Como una estrella furiosa. La cara color ceniza. Expresaba el sino de su casta" (1157).

mientos de los bailarines en el suelo (inusuales en el flamenco), sus gestos faciales y las guitarras son los medios para hablar de una pasión contenida, expresada como sueño o añoranza. 
La coreografía recrea, con el cese repentino de la música y la algarabía, el cambio de ánimo que suscita saber que la Novia ha escapado. Las palabras de la Madre: "Dos bandos. Aquí hay dos bandos. Mi familia y la tuya" (1154), toman forma visual con el intercambio de miradas de desconfianza y desconcierto entre todos los invitados, acompañadas por un simultáneo chasquido de dedos que acentúa el clima tenso en que se transformó la fiesta. La cámara, por su parte, incrementa esta tensión mediante paneo y primeros planos de las manos y rostros. Al finalizar la escena, los invitados quedan separados en dos grupos; la misma Madre entrega la navaja al Novio y le señala el rumbo por el que debe salir a limpiar su nombre.

\section{Muerte y tragedia}

El artículo de 1928 del periódico $A B C$ se publicó bajo el siguiente título: "Crimen desarrollado en circunstancias misteriosas", fue una escueta nota del caso. Respecto al asesinato se limita a consignar lo siguiente: "Detenida la novia, manifestó que había huido en unión de su primo para burlar al novio. La fuga la emprendieron en una caballería, y al llegar al lugar del crimen les salió al encuentro un enmascarado, que hizo cuatro disparos, produciendo la muerte de Montes Cañada [el primo]."

La nota, como salta a la vista, no es excepcional tan sólo los términos "misteriosas" y "enmascarado" producen cierta curiosidad; sin embargo la circunstancia de la huida y la emboscada cobarde de que es víctima la pareja resulta bastante ordinaria. Caso muy distinto ocurre cuando el hecho es transmutado por la imaginación y el lenguaje del poeta. Lorca "organiza nuestra mirada" - como pide Dubatti- y nos expone a fuerzas antagónicas y esenciales de la naturaleza humana: celos, virilidad, erotismo, venganza, violencia.

La poesía y el teatro de Lorca siempre estuvieron en tratos con la muerte. Mas no con la muerte lenta, enfermiza o discreta, sino con la otra: beligerante, traicionera y adelantada; aquella teñida de rojo y que, paradójicamente, se sustenta de la vida a la vez que la sostiene - porque, como escribió Octavio Paz: "El culto a la vida, si en verdad es profundo y total, es también culto a la muerte. Ambas son inseparables. Una civilización que niega a la muerte acaba por negar también a la vida"- (54).

Bodas de sangre une en su título dos condiciones de la existencia: la boda, como promesa de la unión fértil, de dos que dejan su individualidad para ser con otro; frente a la sangre, símbolo antagónico de la pareja indisoluble de Eros y Thanatos. Las nupcias, que legitiman la unión de la pareja ante Dios y los hombres, son atropelladas por la fuerza soberana del deseo, por una savia erótica que obliga a la fusión de los cuerpos, sin importar las consecuencias. Porque a estas "bodas" las avala una ley natural, superior e insoslayable que desafía el orden social, tal como discurren los Leñadores a modo de coro clásico: 
LEÑADOR 1. Se estaban engañando uno a otro y al fin la sangre pudo más.

LEÑADOR 3. ¡La sangre!

LEÑADOR 2. Pero sangre que ve la luz, se la bebe la tierra.

LEÑADOR 1. ¿Y qué? Vale más ser muerto desangrado, que vivo con ella podrida (1156).

En la obra de Lorca, ambos hombres mueren en un duelo. Pero al modo de las tragedias clásicas, dicha escena no se muestra al público y es referida solamente por algunos parlamentos de la Madre, la Novia y tres personajes femeninos secundarios, que remiten a las Parcas (Mendiga, Muchacha 1 y 2).

MUCHACHA 1. Amante sin habla

Novio carmesí.

Por la orilla muda

tendidos los vi (1173).

MENDIGA: Flores rotas los ojos, y sus dientes

dos puñados de nieve endurecida.

Los dos cayeron, y la novia vuelve

teñida de sangre falda y cabellera.

Cubiertos con dos mantas ellos vienen

sobre los hombros de los mozos altos.

Así fue; nada más. Era lo justo.

Sobre la flor del oro, sucia arena (p.1176).

Lorca evita mostrar el combate, confiando a la palabra poética la fuerza y el dibujo de la escena y el desenlace. El público (o el lector) se sobrecoge de miedo y compasión con los parlamentos de las mujeres luctuosas que han quedado solas:

MADRE. Vecinas, con un cuchillo, con un cuchillito, en un día señalado, entre las dos y las tres, se mataron los dos hombres del amor.

Con un cuchillo, con un cuchillito que apenas cabe en la mano, pero que penetra fino por las carnes asombradas, 
y que se para en el sitio

donde tiembla enmarañada

la oscura raíz del grito.

NOVIA. Y esto es un cuchillo,

un cuchillito

que apenas cabe en la mano;

pez sin escamas ni río,

para que un día señalado, entre las dos

y las tres, con este cuchillo,

se quedan dos hombre duros con los labios amarillos.

MADRE. Y apenas cabe en la mano,

pero que penetra frío

por las carnes asombradas

y allí se para en el sitio

donde tiembla enmarañada

la oscura raíz del grito (1181-1182).

La pieza de danza-teatro fue más explícita en su representación, llevando a la escena el enfrentamiento cuerpo a cuerpo. Quizá esto se debió a que los movimientos estilizados de la danza, y el dominio de la técnica de los bailarines, son capaces de distanciarnos de un realismo burdo y lograr así una metáfora, que es lo propio de la poiesis de acuerdo a Dubatti: "Las acciones son además no naturales, es decir, diferenciadas de las acciones reales, ya por su misma génesis - acciones que no observamos en el mundo cotidiano- o porque al ser tomadas por la matriz de la poíesis mutan: acciones despragmatizadas de su función en la empiria y transformadas en poesía" (“Cuerpo social” párrafo 10).

Se trata de una escena de potente significación dramática, la más importante del ballet y la que representó -en palabras del propio Gades- la actuación más difícil de su carrera artística. Veamos el tratamiento que con el lenguaje dancístico se dio a este pasaje, teniendo en mente que un cuerpo sedente o uno en movimiento son también una "escritura corporal" que puede ser interpretada (ver Leigh). En el baile flamenco, el taconeo o las palmas marcan el ritmo como un instrumento de percusión, mientras que el cuerpo es un instrumento silencioso; toque, manos y brazos tienen mayor carga expresiva.

Tras una discusión acalorada, marcada por el taconeo exaltado de ambos rivales y los ruegos infructuosos de la Novia, ambos bailarines se quitan los chalecos mientras desenvainan a la vez sus relucientes cuchillos, que presentan al contrario (como el instrumento de un ritual de honor y hombría). Con estos signos no lingüísticos se parafrasea, es decir, 
INVESTIGACIÓNTEATRAL

Revista de artes escénicas y performatividad

Vol. 10, Núm. 15

abril-septiembre 2019
¿Cómo será la muerte, ese cesar de sentir?

(En torno a Bodas de sangre, de Antonio Gades)

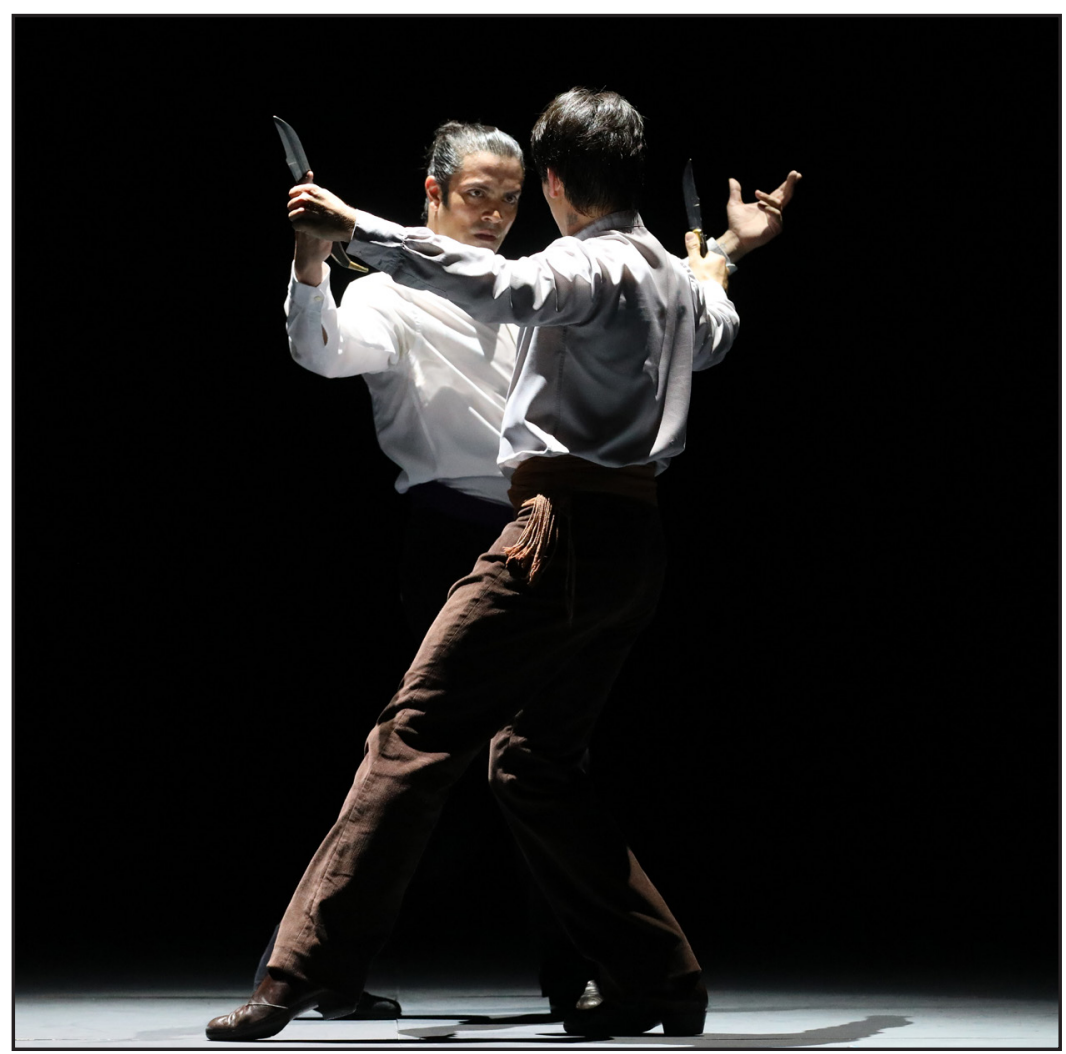

Bodas de sangre ${ }^{\circ}$. Stanislav Levshin | Fundación Antonio Gades

se envían a otro registro las palabras que el poeta puso en boca de la Mendiga: "Ilumina el chaleco y aparta los botones, que después las navajas ya saben el camino."

En silencio se ejecuta una coreografía de una tensión y un virtuosismo notables. La atención se centra en el tour de force de los dos bailarines. Su energía vital y talento, toda su técnica y experiencia se dieron cita para transmitir la intensidad de quien, con la misma fuerza con que lucha por destruir a su enemigo, defiende el honor, la hembra y la vida. Ambos ejecutan muy lentamente movimientos simétricos y simultáneos, como en espejo. Amar a la misma mujer los iguala. Ambos son jóvenes y apuestos, son miembros de familias rivales y sus vidas son igualmente valiosas, como dice la Niña: "Morenito el uno/ morenito el otro" (1177).

La cámara capta un par de veces, en segundo plano y en medio de los rivales, a la Novia. Con close-ups se enfatiza la angustia de sus rostros. En un tercer plano, se observa a los otros miembros de la compañía provocando un momentáneo distanciamiento que no minimiza la potencia iluminadora y catártica de la escena. Dolor y placer se dan cita, como en un lamento de cante jondo. 
Sin montajes atrevidos ni efectos, sin ralenti o congelados, el lente es un mudo testigo absorto y extasiado, que capta el clímax de la muerte. Los adversarios se encuentran en un baile circular, la rabia los habita. Forcejean: peligrosamente las cuchilladas se acercan, los rozan, se hienden. Esta intensa escena, que se prolonga por más de cuatro minutos, ocurre en un silencio siniestro, únicamente interrumpido por la respiración de los combatientes. Asistimos a la reyerta, al hendirse de los aceros en la carne, al desplomarse de los cuerpos, a la rápida agonía. Cuando se hieren mortalmente uno al otro, la aterradora escena se inunda de un palmeo rápido e intenso de todos los bailarines secundarios y unos gritos de jaleo incomprensibles que no son de dolor ni de confusión, sino sincrónicos y repetidos como parte de un antiquísimo ritual. Ambos sonidos van in crescendo y los hombres mueren sin aspavientos ni patetismo.

Dos jóvenes viriles yacen en el suelo. Sorprende que el acto de matar requiera de una vitalidad inigualable, de un arrojo desmedido, de una osadía extrema, porque en la muerte del otro va la sobrevivencia de uno mismo. Vemos en los personajes a la muerte, ese cesar de sentir, al extraño alejamiento que no percibe ya lo que le rodea, al cadáver que no es ya la muerte sino un muerto, a la vida que se alejó de golpe, que llegó a su fin sin continuidad. Vemos a los vivos, que tienen que seguir viviendo. Imposible saber de qué se despide un hombre con el último aliento.

Los receptores quedamos sumisos ante una experiencia contundente de temor y gozosa contemplación estética que nos enfrenta a nuestra frágil condición. La experiencia de muerte está en cada uno de nosotros, única e intransmisible. Sólo el arte nos regala, en una experiencia de horror sublime, asomarnos momentáneamente a sus ojos.

Largo y curioso es el trayecto de transformación que han recorrido los hechos del "crimen de Níjar", desde la realidad consignada en una breve nota periodística, hasta la coreografía plasmada y fijada en una película. La realidad fue sólo el detonante para la creatividad de Lorca; para que el "Duende" -como él lo nombra- lo habitara a él, y luego a Gades y posteriormente a Saura. El Duende, fuerza compatible con el alma española, energía creativa que no es musa, ni ángel, ni demonio teológico. Como lo explica el propio Federico en su "Teoría y juego del duende":

[...] el duende es un poder y no un obrar, es un luchar y no un pensar. Yo he oído decir a un viejo maestro guitarrista: "El duende no está en la garganta; el duende sube por dentro desde la planta de los pies". Es decir, no es cuestión de facultad, sino de verdadero estilo vivo; es decir, de sangre; es decir, de viejísima cultura, de creación en acto (37).

Fue el Duende, el mundo andaluz y el flamenco los que establecieron los sólidos y profundos vasos comunicantes entre estos artistas, así como entre ellos y su teatralidad poética. Fueron el Duende y la teatralidad de esta danza los que mediaron para que nos allegáramos a la zona normalmente inaccesible de matar y morir. 


\section{Fuentes consultadas}

"Crimen desarrollado en circunstancias misteriosas". $A B C, 25$ de julio de 1928 [edición de la mañana], p. 22.

Artaud, Antonin. El teatro y su doble. Traducido por Enrique Alonso y Francisco Abelenda. Ciudad de México: Hermes, 1978.

Auclair, Michelle. Vida y muerte de Federico García Lorca. Ciudad de México: Era.

Azcue, Verónica. "Apuntes sobre la filmación de un mito. Bodas de sangre: del teatro a la danza y de la danza al cine". Revista Latente, núm. 1, 2003, pp 45-56.

Brao, Estefanía. Baile flamenco: observación y análisis del Taranto en los ámbitos profesional y académico. Reflexión metodológica. Tesis de doctorado, Universidad de Murcia, 2014.

Domínguez, Isabel, et al. Antonio Gades. Federico García Lorca. Bodas de sangre. Guía didáctica. Madrid: Fundación Antonio Gades, Comunidad de Madrid, Ayuntamiento de GETAFE, 2009, www. antoniogades.com/images/guias_didacticas/Guia_didactiCa_BODAS_DE_SANGRE_Fundacion-Antonio-Gades.pdf, consultado el 15 de septiembre de 2016.

Dubatti, Jorge. "Teatro-matriz y teatro liminal. La liminalidad constitutiva del acontecimiento teatral". Revista Conjunto, núm. 185, octubre-diciembre 2017, pp. 80-94, www.casa.co. cu/publicaciones/revistaconjunto/185/13Jorge.pdf, consultado el 6 de mayo de 2018.

Dubatti, Jorge. "Cuerpo social y cuerpo poético en la escena argentina". E-misférica, vol. 4, núm. 2, noviembre 2007, www.hemisphericinstitute.org/journal/4.2/esp/es42_pg_ dubatti.html, consultado el 2 de septiembre de 2018.

Dubatti, Jorge. "Convivio y tecnovivio: el teatro entre la infancia y el babelismo", Revista Colombiana de las Artes Escénicas, vol. 9, enero-diciembre 2015, pp. 44-54, artescenicas.ucaldas.edu.co/downloads/artesescenicas9_5.pdf, consultado el 12 de diciembre de 2018.

García Lorca, Francisco. Federico y su mundo. Madrid: Alianza, 1980.

García Lorca, Federico. "Bodas de sangre”. Obras completas. 4a. ed. Madrid: Aguilar, 1962, pp. 1081-1182.

García Lorca, Federico. “Teoría y juego del duende”. Obras completas. 4a. ed. Madrid: Aguilar, 1962. pp. 36- 48.

Lábatte, Beatriz. "Teatro-danza. Los pensamientos y las prácticas". Cuadernos del Picadero, año 3, núm. 10, septiembre, 2006.

Leigh, Susan. "Coreografiar la historia". Lecturas, danza y coreografía, Artea, 2013, loinsignificante.files.wordpress.com/2014/07/lecturassobredanzaycoreografiaok.pdf, consultado el 22 de septiembre de 2016. 
INVESTIGACIÓNTEATRAL

Revista de artes escénicas y performatividad

Vol. 10, Núm. 15

abril-septiembre 2019
¿Cómo será la muerte, ese cesar de sentir?

(En torno a Bodas de sangre, de Antonio Gades)

Nidia Vincent

López Ruiz, Luis. Guía del flamenco. Madrid: Akal, 2007.

Naverón, Isabel de y Amparo Écija, "Leer, bailar, escribir". Lecturas, danza y coreografía, Artea, 2013, loinsignificante.files.wordpress.com/2014/07/lecturassobredanzaycoreografiaok.pdf, consultado el 28 de septiembre de 2016.

Paz, Octavio. “Todos Santos. Día de Muertos". El laberinto de la soledad. Ciudad de México: Fondo de Cultura Económica, 1982, pp. 42-58.

Pineda, Daniel, "Lorca y el flamenco". MonteAgudo, 3a. época, núm. 12, 2007, pp. 169-184

Rolph, Wendy. "Lorca/Gades/Saura: Modes of Adaptation in Bodas de sangre". Anales de la Literatura Española, núm. 11 (1-2), pp. 205-213.

Sedeño, Ana María, "La Generación del 27 y la música: el flamenco". Sinfonía virtual, núm. 7, 2008, www.sinfoniavirtual.com/revista/007/generacion_27_y_musica_flamenco. php, consultado el 18 julio de 2018.

Crónica del suceso de Bodas de sangre, libreto de Alfredo Mañas a partir del drama de Federico García Lorca. Dirigida por Carlos Saura. Antonio Gades, Compañía Antonio Gades,1974, estreno en Teatro Olimpia, Roma, 1974. 